\title{
Using Roy's Model to Evaluate the Care Given to Postpartum Women Following Caesarean Delivery
}

\author{
Serap Ejder Apay*, Türkan Pasinlioglu \\ Department of Obstetric and Gynecological Nursing, Faculty of Health Science, Ataturk University, \\ Erzurum, Turkey \\ Email: sejder@hotmail.com, tpasin@atauni.edu.tr
}

Received 3 September 2014; revised 2 October 2014; accepted 17 October 2014

Copyright (C) 2014 by authors and Scientific Research Publishing Inc.

This work is licensed under the Creative Commons Attribution International License (CC BY). http://creativecommons.org/licenses/by/4.0/

c) (i) Open Access

\begin{abstract}
Background: To evaluate the care given using Roy's Adaptation Model. Materials and Methods: A pretest-posttest experimental model with a control group. Study population comprised postpartum women $(N=134 ; 65$ in the experimental group, 69 in the control group) who had caesarean full-term delivery in a Turkish maternity hospital between September 2009 and February 2011. Data were collected from the experimental group during seven home visits and from the control group at the end of the $6^{\text {th }}$ week postpartum. Results: Percentage, chi-square, arithmetic mean, standard deviation, and the McNamer test were used to evaluate data establishing 36 nursing diagnoses: Physiological requirements (22), Self requirements (7), Role Function requirements (4), and Interdependence Mode requirements (3). It was determined that the care given during the postpartum period using Roy's Adaptation Model resolved or prevented the majority of postpartum problems. The difference between most diagnoses was found to be statistically significant ( $p<$ $0.05 ; p<0.001$ ) during the last week of data collection. Conclusion: The care given in the postpartum period using Roy's Adaptation Model resolved or prevented postpartum problems.
\end{abstract}

\section{Keywords}

Postpartum Period, Roy's Adaptation Model, Nursing Care

\section{Introduction}

A healthy fertility period is extremely important in a woman's life and positively affects not only the woman's own health, but also the health of her family and the rest of society. The delivery method primarily preferred in

"Corresponding author. 
terms of maternal and infant health is vaginal delivery [1]. However, when vaginal delivery is considered to be dangerous for the mother and/or the foetus, a caesarean operation becomes obligatory [2]-[4]. There have also been more recent social reasons contributing to a significant increase in the caesarean delivery rate [5].

In the majority of developed countries, $15 \%$ - 25\% of births are caesarean deliveries [2]. By contrast, a significant increase in the caesarean delivery rate in Turkey has been reported, indicating that caesarean delivery rate increased from $6.9 \%$ in 1993 to $14.0 \%$ in $1998,21.2 \%$ in 2003 and $36.7 \%$ in 2008 [6].

Caesarean delivery is an operation that carries risks for both the mother and the foetus. In caesarean deliveries the maternal mortality rate is higher, medical intervention is greater and the duration of hospital stay and the healing period are longer. Later mobilisation, higher rate of risks for development of infection, delay in motherbaby interactivity and lactation, a longer period of transition to oral feeding and having a surgical procedure are all unwanted effects of caesarean section. These effects might increase the mother's anxiety and fear, and negatively affect her health [7] [8].

The postpartum period is a critical period in terms of maternal health. It is a difficult period when the mother has to undertake new roles and responsibilities in addition to adapting to her physiological changes [7]. The first week of the postpartum period, especially the first 24 hours, is a physiological and psychological transition period when postpartum complications are at their highest level. Studies have concluded that mothers indulge in "navel-gazing" for at least 24 hours due to the physiological and psychological changes they are experiencing, and that their motivation levels to learn are at their lowest [9]-[11]. As understood from these studies, it is vital to also continue the care given at the hospital to a woman giving birth at home. Therefore, in the literature reports have emphasized that when nurses or midwives follow-up the care of postpartum women at home during this postpartum period there are beneficial results [11]-[16].

The majority of the problems encountered during the postpartum period can be prevented or reduced by effective nursing/midwifery care and training. Seemingly simple problems can be recovered by timely intervention before they become complicated, such complications can affect both the mother and child's life for many years. Various studies have shown that during the postpartum period mothers and infants who are monitored and cared for at home after early discharge have lower rates of returning to hospital and hospitalization due to health problems [12] [15] [17]-[19]. Extensive, standardised and qualified nursing care and training given to the mother during the postpartum period enables conscious self-care, competency in motherhood and care and development of herself and her infant, as well as positive health behaviours and health status.

Midwives and nurses are the closest people to the mother during the postpartum period. It is therefore important for them to consider the social and psychological requirements of the family, as well as that of the mother and the newborn in the postpartum period. In order for these requirements to be understood, the mother should be closely followed during the postpartum period.

Roy explains behavioral responses in four adaptive modes. These are the physiological, the self-concept, the role function and the interdependence adaptive modes. The physiological mode is related to the physical responses displayed by a person towards the stimulants arising from their environment. The self-concept mode is the combination of an individual's beliefs and feelings about themselves in a specific period. Within the role function mode, Roy defines the concept of role as when "a person displays the behaviours expected by society due to his/her position in society, in order to maintain his/her position (mother, student, etc.)" or "a person knows how to act when he/she passes from one position to another". The interdependence mode includes the relations of the individual with privileged people and support systems [20].

Numerous studies in the literature have been conducted in various fields using Roy's Adaptation Model [21] [22]. As a result, it has been determined that Roy's Adaptation Model is very useful and facilitates adaptation. In Turkey, while there are studies that have used Roy's Model, there are no regarding postpartum women who have had caesarean delivery. From this point of view, this study was conducted in order to evaluate the effectiveness of the care provided using Roy's Adaptation Model through home visits to postpartum women who had had caesarean delivery.

Hypothesis: The care given to postpartum women who had caesarean delivery using Roy's Adaptation Model reduces or prevents the frequency of postpartum problems.

\section{Materials and Method}

\subsection{Study Design}

The study was conducted as a quasi-experimental model with a control group among postpartum women 
following caesarean delivery in the maternity hospital in a city in Eastern Turkey between September 2009 and February 2011. Study data were collected initially in the hospital and then in the homes of the postpartum women.

\subsection{Setting and Samples}

The study population consisted of postpartum women who had had caesarean full-term delivery at the study hospital between the dates stated and who resided in the city center.

The minimum sample size was calculated via power analysis and determined to be 84 . In this study, the representative power of the sample population was found to be 0.90 with 0.95 confidence interval at $\alpha=0.05$ level [23]. However, considering the possibility that some postpartum women might withdraw from the study for a variety of reasons, the sample size was increased by 60\% to 134 (65 for the experimental group, 69 for the control group). The sample group for the study was selected using the non-probability random sampling method from the population stated above. The control group was included in the study at first and then continued with the experimental group.

Inclusion criteria for the sample group: Mothers aged 15 - 49 years old, mothers or their infants with no illnesses or disabilities, mothers with no loss of sense related to vision or hearing; mothers open to communication and cooperation.

\subsection{Data Collection}

The data were collected using face-to-face interviews conducted by the researchers. The Personal Information Form and Postpartum Follow-up Form designed by the researchers were used to collect data. The Personal Information Form was completed by all postpartum women approximately 24 hours after their caesarean section. The Postpartum Follow-up Form used in establishing the nursing diagnoses was administered in the homes of the postpartum women after they had been discharged. This form was given to the postpartum women in the experimental group during seven home visits in total (first week twice a week, then once a week), twice in the first week after delivery and once in the $2^{\text {nd }}, 3^{\text {rd }}, 4^{\text {th }}, 5^{\text {th }}$ and $6^{\text {th }}$ weeks. The form was administered for those in the control group only once at the end of the $6^{\text {th }}$ week.

\subsection{Data Collection Tools}

Personal Information Form. This form was prepared by the researchers and comprised 10 questions to determine the socio-demographic characteristics of the postpartum women.

Postpartum Follow-Up Form. This form developed by the researchers based on Roy's Adaptation Model in line with the related literature and is a form including the subsystems Adaptive Modes [22] [24]-[32]. Adaptive Modes have four subparts: the physiological mode, the self-concept mode, the role function mode and the interdependence mode. Expert opinion was sought during development of this form. In order to test the comprehensibility of the Postpartum Follow-up Form, a pilot test was performed on seven postpartum women. Following the pilot test, necessary corrections were made in designing the final shape of the form. Those who were in the pilot test were not included in the sample group.

\subsection{Nursing Intervention}

In the nursing care given to postpartum women, suitable nursing diagnoses approved by NANDA were made, depending on the individual. The first nursing intervention focused on the determined nursing diagnoses was applied in the homes of the postpartum women using the care plan form containing these preprepared nursing diagnoses. Nursing process was used in nursing interventions and the Postpartum Follow-up Form was used in evaluating the intervention results. If the determined problem had resolved, a problem is resolved evaluation was made; if not, a problem is ongoing evaluation was made.

A total of seven home visits were made to the postpartum women in the experimental group twice in the first week after delivery and once in the $2^{\text {nd }}$ (between 8 - 14 days), $3^{\text {rd }}$ (between 15 - 21 days), $4^{\text {th }}$ (between 22 - 28 days), $5^{\text {th }}$ (between 29 - 35 days) and $6^{\text {th }}$ (between 36 - 42 days) weeks. Existing diagnoses and possible new diagnoses were evaluated by the Postpartum Follow-up Form. During each visit the diagnoses determined at the previous visit were evaluated regarding their resolution. Necessary interventions were maintained for the con- 
tinuing diagnoses. Nursing interventions focusing on newly occurring diagnoses and possible new diagnoses were made as required and these were evaluated during the following visit. At the end of each visit an appointment was made for the next visit. In addition, the telephone numbers of the researchers were given to the postpartum women so that they could contact them at any time. Care results were evaluated after the postpartum period ended.

The home visit was made to the postpartum women in the control group at the end of the $6^{\text {th }}$ week of postpartum, the existing diagnoses were evaluated after the necessary data was collected and nursing interventions oriented to the diagnoses were performed.

\subsection{Data Analysis}

Coding and evaluation of the data were performed using the SPSS 11.0 software program. In the data evaluation the percentage, arithmetic mean and standard deviation, Chi-square and McNamer tests were used. The confidence interval was $95 \%$ and a $p<0.05$ was considered statistically significant.

\subsection{Ethical Considerations}

Before commencing the study, written permission was obtained from the hospital in which the study would be conducted. In addition, the study was submitted to the Clinical Research Ethics Committee within the body of Provincial Directorate of Health of Erzurum and approval was obtained. In order to protect the rights of the postpartum women participating in the study, the purpose and the duration of the study and the procedures to be conducted during the study were explained to them before collecting study data. All women were informed that they could withdraw from the study at any time.

\subsection{Limitations of the Study}

The limitations of this study include the non-probability sampling method used, pretest nursing diagnoses in the control group were not established, and no home visit was made to the postpartum women in the control group during the postpartum period. Considering that not making any intervention for the problems of the postpartum women in the control group would be unethical, a home visit was made to the control group just once at the end of the postpartum period.

\section{Results}

As shown in Table 1, 47.7\% of the postpartum women in the experimental group were aged 18 - 23 years, 46.2\% were secondary school graduates, $67.7 \%$ were unemployed and $75.4 \%$ were on social security. In the control group, 36.3\% of the postpartum women were aged $24-29$ years, 33.3\% were secondary school graduates and the majority (66.7\%) were unemployed. The difference between the experimental and control groups was not statistically significant and the groups had similar characteristics in terms of variables $(p>0.05$, Table 1$)$. All the pregnant women in the experimental and control groups were operated on under general anesthesia for their caesarean section.

Considering the comparison of the diagnoses of the postpartum women in the experimental group in the first and the last interviews (Table 2), while there was no significant difference between diagnoses of constipation, functional incontinence and stress incontinence $(p>0.05)$, the difference between other diagnoses was found to be statistically significant $(p<0.001, p<0.05)$.

In terms of the physiological requirements (Table 3), in the $7^{\text {th }}$ week of postpartum, the following diagnoses were determined in the women in the control group: the risk of infecting and transmitting infection 10.1\%; ineffective breastfeeding 15.9\%; imbalanced nutrition: more than the body's requirement 17.4\%; disturbed sleep pattern 62.3\%; fatigue was 73.9\%; change in comfort (pain in the abdomen) 14.5\%; change in comfort (breast pain) $55.1 \%$; impaired skin integrity $10.1 \%$; and deterioration impaired physical mobility $14.5 \%$.

In terms of the self-concept requirements (Table 3), in the $7^{\text {th }}$ week postpartum the following diagnoses were determined in the control group: loneliness $8.7 \%$; situational low self-esteem 20.3\%; knowledge deficit (nutrition) 15.9\%; knowledge deficit (hygiene) 23.2\%; knowledge deficit (breastfeeding) 15.9\%; knowledge deficit (family planning) $84.1 \%$; and disturbed body image $20.3 \%$.

In terms of the role function requirements (Table 3), in the $7^{\text {th }}$ week of postpartum, the following diagnoses 
Table 1. Comparison of demographics characteristics confined women in experimental and control groups.

\begin{tabular}{|c|c|c|c|c|c|c|c|}
\hline \multirow{2}{*}{ Characteristics } & \multicolumn{2}{|c|}{ Experimental Groups $(n=65)$} & \multicolumn{2}{|c|}{ Control Groups $(n=69)$} & \multicolumn{2}{|c|}{ Total $(n=134)$} & \multirow{2}{*}{$\begin{array}{c}\text { Test and } \\
p \text { value }\end{array}$} \\
\hline & $\mathbf{n}$ & $\%$ & $\mathbf{n}$ & $\%$ & $\mathbf{n}$ & $\%$ & \\
\hline \multicolumn{8}{|l|}{ Age group (year) } \\
\hline 18 - 23 age & 31 & 47.7 & 23 & 33.3 & 54 & 40.3 & $\mathrm{X}^{2}=4.27$ \\
\hline 24 - 29 age & 23 & 35.4 & 25 & 36.3 & 48 & 35.8 & $\mathrm{df}=2$ \\
\hline$\geq 30$ age & 11 & 16.9 & 21 & 30.4 & 32 & 23.9 & $p>0.05$ \\
\hline \multicolumn{8}{|l|}{ Education level } \\
\hline Primary school & 4 & 6.2 & 5 & 7.2 & 9 & 6.7 & $\mathbf{X}^{2}=2.88$ \\
\hline Secondary school & 30 & 46.2 & 23 & 33.3 & 53 & 39.6 & $\mathrm{df}=3$ \\
\hline High school & 15 & 23.1 & 20 & 29.0 & 35 & 26.1 & $p>0.05$ \\
\hline University & 16 & 24.6 & 21 & 30.4 & 37 & 27.6 & \\
\hline Employment condition & & & & & & & $\mathbf{X}^{2}=0.01$ \\
\hline Employed & 21 & 32.3 & 23 & 33.3 & 44 & 32.8 & $\mathrm{df}=1$ \\
\hline Unemployed & 44 & 67.7 & 46 & 66.7 & 90 & 67.2 & $p>0.05$ \\
\hline \multicolumn{8}{|l|}{ Income $^{*}$} \\
\hline Low & 14 & 21.5 & 8 & 11.6 & 22 & 16.4 & $\mathbf{X}^{2}=3.77$ \\
\hline Middle & 50 & 76.9 & 57 & 82.6 & 107 & 79.9 & $\mathrm{df}=2$ \\
\hline High & 1 & 1.5 & 4 & 5.8 & 5 & 3.7 & $p>0.05$ \\
\hline Social security & & & & & & & $\mathbf{X}^{2}=0.15$ \\
\hline Yes & 49 & 75.4 & 54 & 78.3 & 103 & 76.9 & $\mathrm{df}=1$ \\
\hline No & 16 & 24.6 & 15 & 21.7 & 31 & 23.1 & $\mathrm{p}>0.05$ \\
\hline Gravidity & & & & & & & $\mathbf{X}^{2}=0.02$ \\
\hline Primigravida & 35 & 53.8 & 38 & 55.1 & 73 & 54.5 & $\mathrm{df}=1$ \\
\hline Multigravida & 30 & 46.2 & 31 & 44.9 & 61 & 45.5 & $p>0.05$ \\
\hline Want pregnancy status & & & & & & & $\mathrm{X}^{2}=0.94$ \\
\hline Wanted & 65 & 100.0 & 68 & 98.6 & 133 & 99.3 & $\mathrm{df}=1$ \\
\hline Unwanted & - & - & 1 & 1.4 & 1 & 0.7 & $p>0.05$ \\
\hline \multicolumn{8}{|l|}{ Married years } \\
\hline 1 year & 26 & 40.0 & 16 & 23.2 & 42 & 31.3 & $\mathbf{X}^{2}=6.87$ \\
\hline 2 years & 26 & 40.0 & 30 & 43.5 & 56 & 41.8 & $\mathrm{df}=4$ \\
\hline 3 years & 8 & 12.3 & 9 & 13.0 & 17 & 12.7 & $p>0.05$ \\
\hline$\geq 4$ years & 5 & 7.7 & 14 & 20.3 & 9 & 14.2 & \\
\hline Receiving support for domestic work & & & & & & & $\mathbf{X}^{2}=1.80$ \\
\hline Receiving support & 39 & 60.0 & 49 & 71.0 & 88 & 65.7 & $\mathrm{df}=1$ \\
\hline Not receiving support & 26 & 40.0 & 20 & 29.0 & 46 & 34.3 & $p>0.05$ \\
\hline Receiving support for baby care & & & & & & & $\mathbf{X}^{2}=1.34$ \\
\hline Receiving support & 40 & 61.5 & 49 & 71.0 & 89 & 66.4 & $\mathrm{df}=1$ \\
\hline Not receiving support & 25 & 38.5 & 20 & 29.0 & 45 & 33.6 & $p>0.05$ \\
\hline Duration of stay in hospital & & & & & & & $\mathbf{X}^{2}=0.24$ \\
\hline 2 days & 32 & 49.2 & 31 & 44.9 & 63 & 47.0 & $\mathrm{df}=1$ \\
\hline 3 days & 33 & 50.8 & 38 & 55.1 & 71 & 53.0 & $p>0.05$ \\
\hline \multicolumn{8}{|l|}{ Type of Anesthesia } \\
\hline General & 65 & 100.0 & 69 & 100.0 & 134 & 100.0 & \\
\hline Local & - & - & - & - & & - & \\
\hline
\end{tabular}

"Income is validated according to the Confined Women' own statements. 
Table 2. The comparison of NANDA nursing diagnoses of the experimental group determined in the first and the last interviews.

\begin{tabular}{|c|c|c|c|c|c|c|c|c|c|c|}
\hline \multirow{3}{*}{ Requirements } & \multirow{3}{*}{ NURSING DIAGNOSIS } & \multicolumn{4}{|c|}{ First Meetings } & \multicolumn{4}{|c|}{ Last Meetings } & \multirow{3}{*}{$p^{*}$} \\
\hline & & \multicolumn{2}{|c|}{ Yes } & \multicolumn{2}{|c|}{ No } & \multicolumn{2}{|c|}{ Yes } & \multicolumn{2}{|c|}{ No } & \\
\hline & & $\mathbf{n}$ & $\%$ & $\mathbf{n}$ & $\%$ & $\mathbf{n}$ & $\%$ & $\mathbf{n}$ & $\%$ & \\
\hline \multirow{21}{*}{ PHYSIOLOGICAL } & Risk for infection & 65 & 100 & - & - & - & - & 65 & 100 & $p<0.001$ \\
\hline & Risk for transmitting infection & 37 & 56.9 & 28 & 43.1 & - & - & 65 & 100 & $p<0.001$ \\
\hline & Ineffective breast feding & 36 & 55.4 & 29 & 44.6 & - & - & 65 & 100 & $p<0.001$ \\
\hline & Interruption of breast-feeding & - & - & 65 & 100 & - & - & 65 & 100 & Test not done \\
\hline & $\begin{array}{l}\text { Imbalanced nutrition: less than } \\
\text { body requirement }\end{array}$ & 32 & 49.2 & 33 & 50.8 & - & - & 65 & 100 & $p<0.001$ \\
\hline & $\begin{array}{l}\text { Imbalanced nutrition: more than } \\
\text { body requirement }\end{array}$ & 33 & 50.8 & 32 & 49.2 & - & - & 65 & 100 & $p<0.001$ \\
\hline & Self-care deficit (Bathing) & 31 & 47.7 & 34 & 52.3 & - & - & 65 & 100 & $p<0.001$ \\
\hline & Self-care deficit (Hygiene) & 25 & 38.5 & 40 & 61.5 & - & - & 65 & 100 & $p<0.001$ \\
\hline & Disturbed sleep pattern & 51 & 78.5 & 14 & 21.5 & 4 & 6.2 & 61 & 93.8 & $p<0.001$ \\
\hline & Fatigue & 40 & 61.5 & 25 & 38.5 & 2 & 3.1 & 63 & 96.9 & $p<0.001$ \\
\hline & Changes in comfort-Pain (Abdomen) & 65 & 100 & - & - & 3 & 4.6 & 62 & 95.4 & $p<0.001$ \\
\hline & Changes in comfort-Pain (Breast) & 11 & 16.9 & 54 & 83.1 & 2 & 3.1 & 63 & 94.9 & $p<0.05$ \\
\hline & Constipation & 5 & 7.7 & 60 & 92.3 & 1 & 1.5 & 64 & 98.5 & $p>0.05$ \\
\hline & Urinary retention & 7 & 10.8 & 58 & 89.2 & - & - & 65 & 100 & $p<0.05$ \\
\hline & Functional Incontinence(Urinary) & 2 & 3.1 & 63 & 96.9 & - & - & 65 & 100 & $p>0.05$ \\
\hline & Stress incontinence (Urinary) & 2 & 3.1 & 63 & 96.9 & - & - & 65 & 100 & $p>0.05$ \\
\hline & $\begin{array}{l}\text { Ineffective therapeutic } \\
\text { regimen management }\end{array}$ & - & - & 65 & 100 & - & - & 65 & 100 & Test not done \\
\hline & Deficient fluid volume & 65 & 100 & - & - & - & - & 65 & 100 & $p<0.001$ \\
\hline & Impaired skin integrity & 65 & 100 & - & - & - & - & 65 & 100 & $p<0.001$ \\
\hline & Ineffective health maintenance & 32 & 49.2 & 33 & 50.8 & - & - & 65 & 100 & $p<0.001$ \\
\hline & Impaired physical mobility & 65 & 100 & - & - & - & - & 65 & 100 & $p<0.001$ \\
\hline \multirow{7}{*}{ SELF-CONCEPT } & Loneliness & 21 & 32.3 & 44 & 67.7 & - & - & 65 & 100 & $p<0.001$ \\
\hline & Situational low self-esteem & 11 & 16.9 & 54 & 83.1 & 1 & 1.5 & 64 & 98.5 & $p<0.001$ \\
\hline & Knowledge deficit ( Nutrition) & 38 & 58.5 & 27 & 41.5 & - & - & 65 & 100 & $p<0.001$ \\
\hline & Knowledge deficit (Hygiene) & 25 & 38.5 & 40 & 61.5 & - & - & 65 & 100 & $p<0.001$ \\
\hline & Knowledge deficit (Breast feding) & 45 & 69.2 & 20 & 30.8 & - & - & 65 & 100 & $p<0.001$ \\
\hline & Knowledge deficit (Family planning) & - & - & 65 & 100 & - & - & 65 & 100 & Test not done \\
\hline & Disturbed body image & - & - & 65 & 100 & 10 & 15.4 & 55 & 84.6 & $p<0.001$ \\
\hline \multirow{4}{*}{ ROLE-FUNCTION } & Caregiver role strain & 39 & 60 & 26 & 40 & 3 & 4.6 & 62 & 95.4 & $p<0.001$ \\
\hline & Risk for ineffective parenthood & 9 & 13.8 & 56 & 86.2 & - & - & 65 & 100 & $p<0.001$ \\
\hline & Impaired home maintenance & 21 & 32.3 & 44 & 67.7 & - & - & 65 & 100 & $p<0.001$ \\
\hline & Social isolation & 21 & 32.3 & 44 & 67.7 & - & - & 65 & 100 & $p<0.001$ \\
\hline \multirow{3}{*}{$\begin{array}{l}\text { Interdependence } \\
\text { Mode }\end{array}$} & Change the role of parental & 23 & 35.4 & 42 & 64.6 & - & - & 65 & 100 & $p<0.001$ \\
\hline & Interruption family processes & 20 & 30.8 & 45 & 69.2 & - & - & 65 & 100 & $p<0.001$ \\
\hline & Conflict the role of parental & - & - & 65 & 100 & - & - & 65 & 100 & Test not done \\
\hline
\end{tabular}

${ }^{*}$ McNemar 
were determined in the control group: caregiver role strain 13.0\%; impaired home maintenance $26.1 \%$; social isolation $8.7 \%$.

In terms of interdependence mode requirements, in the $7^{\text {th }}$ week of postpartum, for $5.8 \%$ of the postpartum women in the control group diagnosis of change in the family process was determined.

Comparison of the diagnoses determined in the last interview for those in the experimental group and the control group (Table 4) showed the difference between the diagnoses of disturbed body image ( $p>0.05)$, caregiver role strain $(p>0.05)$, and interruption of the family processes were not statistically significant; the difference between other diagnoses was statistically significant $(p<0.001, p<0.05)$.

Table 3. The distribution of the NANDA nursing diagnoses of the control group established at the end of the $6^{\text {th }}$ week $(n=$ 69).

\begin{tabular}{|c|c|c|c|c|c|}
\hline \multirow{3}{*}{ Requirements } & \multirow{3}{*}{ NURSING DIAGNOSIS } & \multicolumn{4}{|c|}{ Second Meetings } \\
\hline & & \multicolumn{2}{|c|}{ Yes } & \multicolumn{2}{|c|}{ No } \\
\hline & & $\mathbf{n}$ & $\%$ & $\mathbf{n}$ & $\%$ \\
\hline \multirow{12}{*}{ PHYSIOLOGICAL } & Risk for infection & 7 & 10.1 & 62 & 89.9 \\
\hline & Risk for transmitting infection & 7 & 10.1 & 62 & 89.9 \\
\hline & Ineffective breast feding & 11 & 15.9 & 58 & 84.1 \\
\hline & Interruption of breast-feeding & 58 & 84.1 & 11 & 15.9 \\
\hline & Imbalanced nutrition: more than body requirement & 12 & 17.4 & 57 & 82.6 \\
\hline & Disturbed sleep pattern & 43 & 62.3 & 26 & 37.7 \\
\hline & Fatigue & 51 & 73.9 & 18 & 26.1 \\
\hline & Changes in comfort-Pain (Abdomen) & 10 & 14.5 & 59 & 85.5 \\
\hline & Changes in comfort-Pain (Breast) & 38 & 55.1 & 31 & 44.9 \\
\hline & Impaired skin integrity & 7 & 10.1 & 62 & 89.9 \\
\hline & Ineffective health maintenance & 12 & 17.4 & 57 & 82.6 \\
\hline & Impaired physical mobility & 10 & 14.5 & 59 & 85.5 \\
\hline \multirow{7}{*}{ SELF-CONCEPT } & Loneliness & 6 & 8.7 & 63 & 91.3 \\
\hline & Risk for situational low self-esteem & 14 & 20.3 & 55 & 79.7 \\
\hline & Knowledge deficit ( Nutrition) & 11 & 15.9 & 58 & 84.1 \\
\hline & Knowledge deficit (Hygiene) & 16 & 23.2 & 53 & 76.8 \\
\hline & Knowledge deficit (Breast feding) & 11 & 15.9 & 58 & 84.1 \\
\hline & Knowledge deficit (Family planning) & 58 & 84.1 & 11 & 15.9 \\
\hline & Disturbed body image & 14 & 20.3 & 55 & 79.7 \\
\hline \multirow{3}{*}{ ROLE-FUNCTION } & Caregiver role strain & 9 & 13.0 & 60 & 87.0 \\
\hline & Impaired home maintenance & 18 & 26.1 & 51 & 73.9 \\
\hline & Social isolation & 6 & 8.7 & 63 & 91.3 \\
\hline Interdependence Mode & Interruption family processes & 4 & 5.8 & 65 & 94.2 \\
\hline
\end{tabular}


Table 4. The comparison of NANDA nursing diagnoses of the experimental group and the control group determined in the last interview.

\begin{tabular}{|c|c|c|c|c|c|c|c|c|c|c|}
\hline \multirow{3}{*}{ Requirements } & \multirow{3}{*}{ NURSING DIAGNOSIS } & \multicolumn{4}{|c|}{ Experimental Group } & \multicolumn{4}{|c|}{ Control Group } & \multirow{3}{*}{$p^{*}$} \\
\hline & & \multicolumn{2}{|c|}{ Yes } & \multicolumn{2}{|c|}{ No } & \multicolumn{2}{|c|}{ Yes } & \multicolumn{2}{|c|}{ No } & \\
\hline & & $\mathbf{n}$ & $\%$ & $\mathbf{n}$ & $\%$ & $\mathbf{n}$ & $\%$ & $\mathbf{n}$ & $\%$ & \\
\hline \multirow{21}{*}{ PHYSIOLOGICAL } & Risk for infection & - & - & 65 & 100 & 7 & 10.1 & 62 & 89.9 & $p<0.001$ \\
\hline & Risk for transmitting infection & - & - & 65 & 100 & 7 & 10.1 & 62 & 89.9 & $p<0.001$ \\
\hline & Ineffective breast feding & - & - & 65 & 100 & 11 & 15.9 & 58 & 84.1 & $p<0.001$ \\
\hline & Interruption of breast-feeding & - & - & 65 & 100 & 58 & 84.1 & 11 & 15.9 & $p<0.001$ \\
\hline & $\begin{array}{l}\text { Imbalanced nutrition: less than } \\
\text { body requirement }\end{array}$ & - & - & 65 & 100 & - & - & - & - & Test not done \\
\hline & $\begin{array}{l}\text { Imbalanced nutrition: more than } \\
\text { body requirement }\end{array}$ & - & - & 65 & 100 & 12 & 17.4 & 57 & 82.6 & $p<0.001$ \\
\hline & Self-care deficit (Bathing) & - & - & 65 & 100 & - & - & - & - & Test not done \\
\hline & Self-care deficit (Hygiene) & - & - & 65 & 100 & - & - & - & - & Test not done \\
\hline & Disturbed sleep pattern & 4 & 6.2 & 61 & 93.8 & 43 & 62.3 & 26 & 37.7 & $p<0.001$ \\
\hline & Fatigue & 2 & 3.1 & 63 & 96.9 & 51 & 73.9 & 18 & 26.1 & $p<0.001$ \\
\hline & Changes in comfort-Pain (Abdomen) & 3 & 4.6 & 62 & 95.4 & 10 & 14.5 & 59 & 85.5 & $p<0.05$ \\
\hline & Changes in comfort-Pain (Breast) & 2 & 3.1 & 63 & 94.9 & 38 & 55.1 & 31 & 44.9 & $p<0.001$ \\
\hline & Constipation & 1 & 1.5 & 64 & 98.5 & - & - & - & - & Test not done \\
\hline & Urinary retention & - & - & 65 & 100 & - & - & - & - & Test not done \\
\hline & Functional Incontinence(Urinary) & - & - & 65 & 100 & - & - & - & - & Test not done \\
\hline & Stress incontinence (Urinary) & - & - & 65 & 100 & - & - & - & - & Test not done \\
\hline & $\begin{array}{l}\text { Ineffective therapeutic regimen } \\
\text { management }\end{array}$ & - & - & 65 & 100 & - & - & - & - & Test not done \\
\hline & Deficient fluid volume & - & - & 65 & 100 & - & - & - & - & Test not done \\
\hline & Impaired skin integrity & - & - & 65 & 100 & 7 & 10.1 & 62 & 89.9 & $p<0.001$ \\
\hline & Ineffective health maintenance & - & - & 65 & 100 & 12 & 17.4 & 57 & 82.6 & $p<0.001$ \\
\hline & Impaired physical mobility & - & - & 65 & 100 & 10 & 14.5 & 59 & 85.5 & $p<0.001$ \\
\hline \multirow{7}{*}{ SELF-CONCEPT } & Loneliness & - & - & 65 & 100 & 6 & 8.7 & 63 & 91.3 & $p<0.05$ \\
\hline & Situational low self-esteem & 1 & 1.5 & 64 & 98.5 & 14 & 20.3 & 55 & 79.7 & $p<0.001$ \\
\hline & Knowledge deficit ( Nutrition) & - & - & 65 & 100 & 11 & 15.9 & 58 & 84.1 & $p<0.001$ \\
\hline & Knowledge deficit (Hygiene) & - & - & 65 & 100 & 16 & 23.2 & 53 & 76.8 & $p<0.001$ \\
\hline & Knowledge deficit (Breast feding) & - & - & 65 & 100 & 11 & 15.9 & 58 & 84.1 & $p<0.001$ \\
\hline & Knowledge deficit (Family planning) & - & - & 65 & 100 & 58 & 84.1 & 11 & 15.9 & $p<0.001$ \\
\hline & Disturbed body image & 10 & 15.4 & 55 & 84.6 & 14 & 20.3 & 55 & 79.7 & $p>0.05$ \\
\hline \multirow{4}{*}{ ROLE-FUNCTION } & Caregiver role strain & 3 & 4.6 & 62 & 95.4 & 9 & 13.0 & 60 & 87.0 & $p>0.05$ \\
\hline & Risk for ineffective parenthood & - & - & 65 & 100 & - & - & - & - & Test not done \\
\hline & Impaired home maintenance & - & - & 65 & 100 & 18 & 26.1 & 51 & 73.9 & $p<0.001$ \\
\hline & Social isolation & - & - & 65 & 100 & 6 & 8.7 & 63 & 91.3 & $p<0.05$ \\
\hline \multirow{3}{*}{$\begin{array}{l}\text { Interdependence } \\
\text { Mode }\end{array}$} & Change the role of parental & - & - & 65 & 100 & - & - & - & - & Test not done \\
\hline & Interruption family processes & - & - & 65 & 100 & 4 & 5.8 & 65 & 94.2 & $p>0.05$ \\
\hline & Conflict the role of parental & - & - & 65 & 100 & - & - & - & - & Test not done \\
\hline
\end{tabular}

${ }^{*}$ Chi-square. 


\section{Discussion}

This study was conducted to evaluate the effectiveness of the care given to postpartum women following caesarean delivery using Roy’s Adaptation Model and the results are discussed in relation to literature. Diagnoses that could not be resolved are discussed in the following.

\subsection{Discussion of Nursing Diagnoses for Physiological Requirements}

In the Experimental Group, for 6 weeks numerous nursing diagnoses were established for physiological requirements. Among these diagnoses, disturbed sleep pattern, fatigue, changes in comfort-pain (abdomen, breast), and constipation could not be resolved, despite all suitable interventions being made during all postpartum visits. When the diagnoses determined at the first and the last interviews were compared, the difference between all other diagnoses - with the exception of constipation $(p>0.05)$, functional incontinence $(p>0.05)$ and stress incontinence $(p>0.05)$ — was statistically significant $(p<0.05)$.

In the Control Group, in the evaluation made in the $7^{\text {th }}$ week the following diagnoses were established: risk of infection and transmitting infection, ineffective breast feeding, interruption of breast feeding, imbalanced nutrition: more than the body's requirement, disturbed sleep pattern, fatigue, changes in comfort-pain (abdomen, breast), impaired skin integrity, insufficiency ineffective health maintenance and impaired physical mobility.

When the diagnoses of the postpartum women in the experimental and control groups determined during the last interview for physiological requirements were compared, the difference between most diagnoses was statistically significant $(p<0.05)$. The fact that the majority of the nursing diagnoses for physiological requirements were resolved shows the effectiveness of the care given according to Roy's Adaptation Model. The reason for the diagnosis of disturbed sleep pattern, one of the diagnoses that could not be resolved, was associated with the high number of visits and the postpartum women not receiving sufficient support for their daily housework and infant care. Similarly, in Nazik's (2009) study, one of the diagnoses that could not be resolved was disorder in the sleep routine. Some other studies have also determined that women in the postpartum period had sleep disorders [18] [33]-[35].

The fatigue diagnosis is also considered as not resolved due to the lack of people to help the postpartum women in their domestic responsibilities and infant care. Again, this was also the case in Nazik's (2009) study, and Rychnovsky and Hunter's (2009) study concluded that sleep disorders in postpartum women in the postpartum period increased their fatigue [33] [36]. Similarly, in the studies of Gungor et al. (2004), Guner (2007) and Doganer (2005), fatigue was one of the problems experienced by postpartum women [18] [34] [35].

The fact that changes in comfort-pain (abdomen) diagnosis could not be resolved is considered to be due to the longer recovery process of postpartum women following caesarean delivery, compared to those who had a vaginal delivery. In Nazik’s (2009) study the reason for resolution of the change in comfort (perineum) diagnosis might be associated with different delivery methods [33]. In the study conducted by Gungor et al. (2004) to evaluate the problems of postpartum women who had had caesarean delivery, abdominal strain, pain and gas complaints were observed [18].

The reason why changes in comfort-pain (Breast) could not be resolved is considered related to the fact that postpartum women who had undergone a surgical operation failed to take the correct position for breastfeeding, which ultimately causes problems in the breasts as a complication. In Nazik's (2009) study, the diagnosis of change in comfort (breast) was remedied; once again this may be due to the differences in the delivery methods [33]. Similar to the study result, Gungor et al. (2004) found that "difficulty in breastfeeding and breast problems" was one of the physical problems identified [18].

It was determined that the constipation diagnosis decreased as the time after surgery increased. This diagnosis could not be resolved in one of the postpartum woman; however, she had had continuous constipation even before pregnancy and thus this lack of resolution might be associated with the related condition. In Doganer's (2005) study, it was also found that postpartum women had constipation in the postpartum period [34].

\subsection{Discussion of Diagnoses for Self-Concept Requirements}

In the experimental group, the following diagnoses for self-concept requirements were established: loneliness, situational low self-esteem, knowledge deficit (nutrition), knowledge deficit (hygiene), knowledge deficit (breastfeeding), knowledge deficit (family planning), and disturbed body image. Of these diagnoses, situational 
low self-esteem and disturbed body image diagnoses could not be resolved. When the diagnoses determined in the first and the last interviews were compared, the difference between all other diagnoses (with the exception of knowledge deficit-family planning) was statistically significant $(p<0.05)$.

In the control group, the following diagnoses were established in the evaluation carried out in the $7^{\text {th }}$ week: loneliness, situational low self-esteem, knowledge deficit (nutrition), knowledge deficit (hygiene), knowledge deficit (breastfeeding), knowledge deficit (family planning), and disturbed body image.

When the diagnoses of the postpartum women in the experimental and control groups determined during the last interview in terms of self-concept requirements were compared, the difference between all other diagnoses (with the exception of disturbed body image) was statistically significant $(p<0.05)$. The fact that the majority of the nursing diagnoses for self-concept requirements were resolved shows the effectiveness of the care given according to Roy's Adaptation Model.

One of the diagnoses that could not be recovered, situational low self-esteem, is considered to be due to hormonal fluctuations, physical and social changes, mood changes after birth, social isolation, fatigue, failure in adapting to the motherhood role and lack of people to help the postpartum women in their domestic responsibilities and infant care. Failure in providing the postpartum women with the required support postpartum in this period might adversely affect their physical and mental health. Similarly, in the study by Najman et al. (2000), reported women experiencing low self-esteem during the postpartum period [37].

The reason behind why the disturbed body image diagnosis could not be resolved is considered to be due to reasons such as having been undergone a surgical operation, not being able to quickly lose the weight gained during pregnancy and the change in the interest of the husband from his wife to the baby. In the studies conducted by Gungor et al. (2004) and Doganer (2005), postpartum women also stated that they experienced negative body image [18] [34].

\subsection{Discussion of Diagnoses for Role Function Requirements}

In the experimental group, the following diagnoses were established for role function requirements: caregiver role strain, risk of ineffective parenthood, impaired home maintenance and social isolation. Of these diagnoses, the risk of ineffective parenthood, impaired home maintenance and social isolation were resolved. The diagnosis of caregiver role strain could not be resolved, despite all the suitable interventions made during all postpartum visits. When the diagnoses determined in the first and last interviews were compared, the difference for all diagnoses was statistically significant $(p<0.001)$.

In the control group, the following diagnoses for role function requirements were established: caregiver role strain, caregiver role strain and social isolation.

When the diagnoses of postpartum women in the experimental and control groups determined in the last interview in terms of role function requirements were compared, the difference between all diagnoses was statistically significant $(p<0.05)$. The fact that the majority of the diagnoses determined in terms of role function requirements were resolved shows the effectiveness of the care given according to Roy's Adaptation Model.

The fact that caregiver role strain diagnosis could not be resolved is considered to be due to the lack of people to help the postpartum women in their domestic responsibilities and infant care. Studies conducted by Gungor et al. (2004), Guner (2007) and Doganer (2005) support this finding that postpartum women had difficulty caring for themselves and their babies [18] [34] [35]. In their study, Logsdon and Koniak-Griffin (2005) indicated that providing the mothers with sufficient support in the postpartum period, when both physical and psychological changes are intensely experienced, would positively affect their physical and mental health [38].

\subsection{Discussion of Diagnoses for Interdependence Requirements}

In the experimental group, the following diagnoses for interdependence requirements were established: change the role of parental, interruption family processes and conflict in the parental role. When the diagnoses identified in the first and last interviews were compared, the difference between the majority of diagnoses was statistically significant $(p<0.001)$.

In the control group, for interdependence requirements, the diagnosis of interruption family processes was established.

When the diagnoses of postpartum women in the experimental and control groups determined in the last interview in terms of interdependence requirements were compared, the difference between diagnosis of interruption 
family processes was statistically significant $(p<0.05)$. The fact that all the diagnoses for interdependence requirements were resolved shows that the care given according to Roy's Adaptation Model was efficient. As a result of the care given to the postpartum women in the postpartum period based on Roy's Adaptation Model, fewer problems were experienced. This result shows that the hypothesis of "The care given using Roy's Adaptation Model to postpartum women who had had caesarean delivery reduces or prevents the frequency of postpartum problems" is verified. Similarly, in the studies conducted by Kiliç (2011), Nazik (2009) and Koç (2005) using the model, the care given during the postpartum period also decreased/prevented the postpartum complications [33] [39] [40]. The mentioned studies produced similar results, since they provided model-based care. In the studies using the models it was observed that the care results were more effective and systematic. Furthermore, in the studies of De la Rosa et al. (2009) and Wager et al. (2004), it was found that postpartum home visits positively affected maternal and infant health [41] [42]. However, although the results in these studies were positive, they had solved fewer problems and were less systematic.

\section{Conclusion and Recommendations}

In this study, for 6 weeks of the postpartum period a total of seven interviews were conducted with the postpartum women in the experimental group and 36 nursing diagnoses were established in total. Physiological requirements comprised 22 of these diagnoses, 7 included Self-concept requirements, 4 included Role Function requirements and three included Interdependence Mode requirements. The majority of the established diagnoses were resolved with the care provided.

In the study, two interviews were conducted with the postpartum women in the control group and 23 nursing diagnoses were established in total. Physiological requirements comprised 12 of these diagnoses, 7 included Self-concept requirements, 3 included Role Function requirements and one included Interdependence Mode requirements.

As a result of the care provided, when diagnoses of the postpartum women in the experimental and control groups determined in the last week of postpartum were compared, the difference between most diagnoses was statistically significant $(p<0.05)$. This result shows that the group receiving care had fewer problems.

As a result of the care provided using Roy's Adaptation Model, the majority of the postpartum problems were reduced.

As a result of the care provided using Roy's Adaptation Model, the majority of the nursing diagnoses determined in the postpartum period were resolved after care.

It was determined that Roy's Adaptation Model was an effective care model for postpartum women who had had caesarean delivery.

\section{Further Research Recommendations}

In order to eliminate/prevent problems that might develop in the postpartum period and to increase the adaptation to postpartum, the following can be recommended:

Nursing care should be given to postpartum women who have had caesarean delivery by using Roy's Adaptation Model;

The care should be given to postpartum women who have had caesarean delivery should be provided using different nursing models and the care results should be compared;

Future studies should be conducted in different geographical regions and in a larger sample group in order for Roy's Adaptation Model to be used as a standard during the postpartum period.

\section{Contributions}

Study design: SEA, TP; data collection and analysis: SEA; and manuscript preparation: SEA, TP.

\section{Conflict of Interest}

None.

\section{References}

[1] Türkiye’de Ana Sağlığı, A.A. (2002) Türkiye Nüfus ve Sağlık Araştırması 1998 İleri Analiz Sonuçları. Hacettepe 
Üniversitesi Yayını, Ankara. (in Turkish)

[2] Demir, N., Koç, A. and Sezaryen, Y.A. (2001) Maternal-Foetal Tıp \& Perinatoloji. Kozan Ofset, Ankara. (in Turkish)

[3] Sachs, B.P., Beard, R., Papiernik, E. and Christine, R. (1995) Caesarean Section. Reproductive Health Care for Women and Babies Policy and Ethics. Oxford University Press, New York.

[4] Scott, J.R., Disaia, J.P., Hammend, B.C. and Spellacy, N.W. (1994) Danforth Obstetrik ve Jinekoloji. Erez, S., Ed., 7. Yücel Yayın A.Ş., Baskı, İstanbul. (in Turkish)

[5] Bonnar, J. (1999) Obstetrics and Gynaecology. Churchill Livingstone, Toronto.

[6] Turkey Demographic and Health Survey. (2008). http://www.hips.hacettepe.edu.tr/tnsa2008/data/TNSA-2008 ana Rapor-tr.pdf

[7] Decherney, H.A. and Nathan, L. (2003) Current Obstetric and Gynaecologic Diagnosis and Treatment. McGraw-Hill Medical, New York.

[8] Önderoğlu, L., Deren, Ö. and Ayhan, A. (1999) Vajinal Doğum mu? Sezaryen mi? Hacettepe Tip Derg, 30, 61-65. (in Turkish)

[9] Martell, L. (2003) Postpartum Women’s Perceptions of the Hospital Environment. Journal of Obstetric, Gynaecologic and Neonatal Nursing, 32, 478-485. http://dx.doi.org/10.1177/0884217503255087

[10] Fishbein, E.G. and Burggraf, E. (1998) Early Postpartum Discharge: How Are Mothers Managing? Journal of Obstetric, Gynecologic, and Neonatal Nursing, 27, 142-148. http://dx.doi.org/10.1111/j.1552-6909.1998.tb02604.X

[11] O’Connor, K., Mowat, D.L., Scott, H.M., Carr, P.A., Dorland, J.L. and Young, K.F. (2003) A Randomized Trial of Two Public Health Nurse Follow-Up Programs after Early Obstetrical Discharge: An Examination of Breastfeeding Rates, Maternal Confidence and Utilization and Costs of Health Services. Canadian Journal of Public Health, 94, 98103.

[12] Bossert, R. and Rayburn, W.F. (2001) Early Postpartum Discharge at a University Hospital: Outcome Analysis. Journal of Reproductive Medicine, 46, 39-43.

[13] Escobar, G.J. and Braveman, P.A. (2001) A Randomized Comparison of Home and Clinic Follow-Up Visits after Early Postpartum Hospital Discharge: Part II. Paediatrics, 108, 719-727. http://dx.doi.org/10.1542/peds.108.3.719

[14] Lichtenstein, B., Brumfield, C., Cliver, S., Chapman, V., Lenze, D. and Davis, V. (2004) Giving Birth, Going Home: Influences on When Low-Income Women Leave Hospital. Health, 8, 81-100.

[15] Mandl, K.D. and Homer, C.J. (2000) Effect of a Reduced Postpartum Length of Stay Program on Primary Care Services Use by Mothers and Infants. Pediatrics, 106, 937-941.

[16] Lieu, T.A. and Braveman, P.A. (2000) A Randomized Comparison of Home and Clinic Follow-Up Visits after Early Postpartum Hospital Discharge: Part I. Paediatrics, 105, 1058-1065. http://dx.doi.org/10.1542/peds.105.5.1058

[17] Bashiri, A., Smolin, A., Sheiner, E., Zelingher, J. and Mazor, M. (2003) Maternal Rehospitalisation after Singleton Term Vaginal Delivery. Journal of Maternal and Foetal Neonatal Medicine, 14, 344-348. http://dx.doi.org/10.1080/jmf.14.5.344.348

[18] Gungor, I., Gokyildiz, S. and Nahcivan, N.Ö. (2004) Sezaryen doğum yapan bir grup kadının doğuma ilişkin görüşleri ve doğum sonu erken dönemde yaşadıkları sorunlar. Ístanbul Universitesi Florence Ninghtingale HYO Derg, 13, 185197. (in Turkish)

[19] Maera, E., Kotagal, U.R. and Atherton, H.D. (2004) Impact of Early Discharge Legislation and Early Follow-Up Visits on Infant Outcomes. Paediatrics, 113, 1619-1630. http://dx.doi.org/10.1542/peds.113.6.1619

[20] Alligood, M.R. and Tomey, A.M. (2002) Nursing Theory Utilization and Application. Mosby-Year Book, Philadelphia.

[21] De Santo-Madeya, S. (2009) Adaptation to Spinal Cord Injury for Families Post-Injury. Nursing Science Quarterly, 22, 57-66. http://dx.doi.org/10.1177/0894318408327295

[22] Newman, D.M. (1997) The Inventory of Functional Status-Caregiver of a Child in a Body Cast. Journal of Paediatric Nursing, 12, 142-147. http://dx.doi.org/10.1016/S0882-5963(97)80071-1

[23] Lenth, R.V. (2006) Java Applets for Power and Sample Size (Computer Software). http://www.stat.uiowa.edu/ rlenth/Power

[24] Barone, S.H., Roy, C.L. and Frederickson, K.C. (2008) Instruments Used in Roy Adaptation Model-Based Research: Review, Critique and Future Directions. Nursing Science Quarterly, 21, 353-362. http://dx.doi.org/10.1177/0894318408323491

[25] Hana, D.R. (2006) Using the Roy Adaptation Model in Management of Work Groups. Nursing Science Quarterly, 19, 226-227. http://dx.doi.org/10.1177/0894318406289886 
[26] Florence, M.E., Lutzen, K. and Alexius, B. (1994) Adaptation of Heterosexually Infected HIV Positive Women: A Swedish Pilot Study. Health Care for Women International, 15, 265-273. http://dx.doi.org/10.1080/07399339409516119

[27] Freitas, M.C. and Oliveira, M.F. (2006) Nursing Care to Elderly Patients Undergoing Heart Catheterization: A Proposal According to the Adaptation Model of Callista Roy. The Brazilian Nursing Journal, 59, 642-646. http://dx.doi.org/10.1590/S0034-71672006000500009

[28] Lamb, M.A. and Sheldon, T.A. (1994) The Sexual Adaptation of Women Treated for Endometrial Cancer. Cancer Practice, 2, 103-113.

[29] Legault, F.M. (1991) Adaptation within the Role Function and Self-Concept Modes among Women during the Postpartum Period. Master's Thesis, D’Youville College, Buffalo.

[30] Mitchell, G.J. and Cody, W.K. (1993) The Role of Theory in Qualitative Research. Nursing Science Quarterly, 6, 170178. http://dx.doi.org/10.1177/089431849300600405

[31] Roy, C., Whetsell, M.V. and Frederickson, K. (2009) The Roy Adaptation Model and Research. Nursing Science Quarterly, 22, 209-211. http://dx.doi.org/10.1177/0894318409338692

[32] Thornbury, J.M. and King, L.D. (1992) The Roy Adaptation Model and Care of Person with Alzheimer's Disease. Nursing Science Quarterly, 5, 129-133. http://dx.doi.org/10.1177/089431849200500310

[33] Nazik, E. (2009) Öz-bakım modeli kullanılarak verilen bakımın postpartum komplikasyonların önlenmesi ve giderilmesine etkisi. Doctoral Thesis, Atatürk Üniversitesi, Erzurum. (in Turkish)

[34] Doganer, G. (2005) Vajinal yolla doğum yapan kadınların postpartum dönemde kendisinin ve yenidoğanın bakımına yönelik yaşadıkları sorunların belirlenmesi. Master’s Thesis, Cumhuriyet Üniversitesi, Sivas. (in Turkish)

[35] Guner, T. (2007) Vajinal yol ve sezaryenla doğum yapan adölesan annelerin doğum postpartum döneminde kendilerinin ve bebeklerinin bakımında yaşadıkları sorunların karşılaştırılması. Master's Thesis, Cumhuriyet Üniversitesi, Sivas. (in Turkish)

[36] Rychnovsky, J. and Hunter, L.P. (2009) The Relationship between Sleep Characteristics and Fatigue in Healthy Postpartum Women. Women's Health Initiative, 19, 38-44.

[37] Najman, J.M., Andersen, M.J., Bor, W., O’Callaghan, M.J. and Williams, G.M. (2000) Postnatal Depression-Myth and Reality: Maternal Depression before and after the Birth of a Child. Social Psychiatry and Psychiatric Epidemiology, 35, 19-27. http://dx.doi.org/10.1007/s001270050004

[38] Logsdon, M.C. and Koniak-Griffin, D. (2005) Social Support in Postpartum Adolescents: Guidelines for Nursing Assessments and Interventions. Journal of Obstetric, Gynaecologic and Neonatal Nursing, 34, 761-768. http://dx.doi.org/10.1177/0884217505281855

[39] Kilic, M. (2011) Erken doğum tanısı alan gebelere verilen bakımın gebelerin öz bakım gücüne etkisi. Doctoral Thesis, Atatürk Üniversitesi, Erzurum. (in Turkish)

[40] Koç, G. (2005) Doğum sonu erken dönemde taburcu edilen anneler için geliştirilen evde bakım hizmet modelinin etkinliğinin incelenmesi. Doctoral Thesis, Hacettepe Üniversitesi, Ankara. (in Turkish)

[41] De la Rosa, I.A., Perry, J. and Johnson, V. (2009) Benefits of Increased Home-Visitation Services: Exploring a Case Management Model. Family and Community Health, 32, 58-75. http://dx.doi.org/10.1097/01.FCH.0000342817.95390.7e

[42] Wager, K.A., Lee, F.W., Bradford, W.D., Jones, W. and Kilpatrick, A.O. (2004) Qualitative Evaluation of South Carolina’s Postpartum/Infant Home Visit Program. Public Health Nursing, 21, 541-546. http://dx.doi.org/10.1111/j.0737-1209.2004.21606.x 
Scientific Research Publishing (SCIRP) is one of the largest Open Access journal publishers. It is currently publishing more than 200 open access, online, peer-reviewed journals covering a wide range of academic disciplines. SCIRP serves the worldwide academic communities and contributes to the progress and application of science with its publication.

Other selected journals from SCIRP are listed as below. Submit your manuscript to us via either submit@scirp.org or Online Submission Portal.
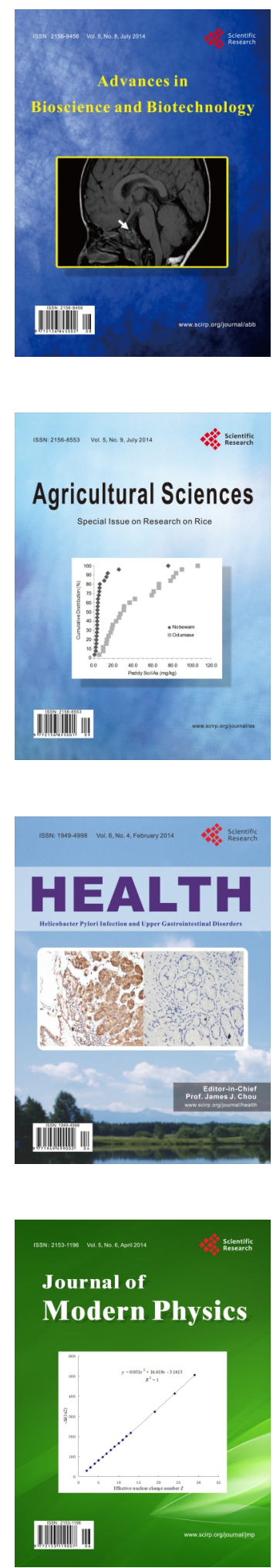
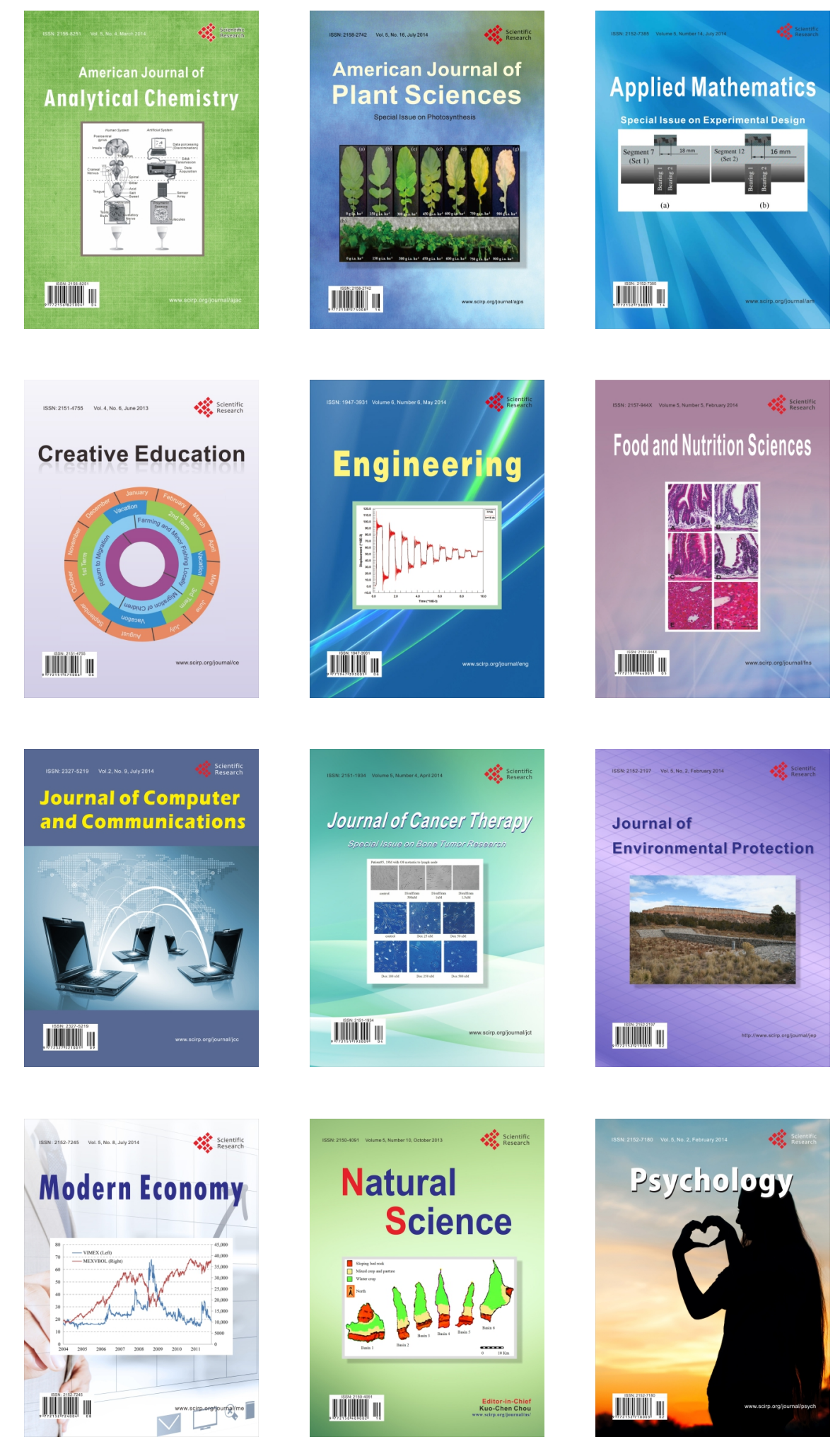